\title{
Mindfulness for Preventing Psychosocial Risks in the Workplace: A Systematic Review and Meta-Analysis
}

\author{
María del Carmen Pérez-Fuentes ${ }^{1, * \mathbb{D}}$, María del Mar Molero Jurado ${ }^{1, * \mathbb{C}}$, \\ Isabel Mercader Rubio ${ }^{1}$, José Gabriel Soriano Sánchez ${ }^{1}$ and José Jesús Gázquez Linares ${ }^{1,2, *}$ \\ 1 Department of Psychology, University of Almería, 04120 Almería, Spain; imercade@ual.es (I.M.R.); \\ jss955@ual.es (J.G.S.S.) \\ 2 Department of Psychology, Universidad Autónoma de Chile, 4780000 Santiago, Chile \\ * Correspondence: mpf421@ual.es (M.d.C.P.-F.); mmj130@ual.es (M.d.M.M.J.); jlinares@ual.es (J.J.G.L.); \\ Tel.: +34-950015598 (M.d.C.P.-F.)
}

Received: 17 February 2020; Accepted: 5 March 2020; Published: 8 March 2020

\begin{abstract}
Organizations today are implementing psychological interventions to promote the job performance and wellbeing of their employees. Mindfulness-based interventions (MBIs) can contribute to providing workers with competencies and skills and develop their strengths. MBIs are therefore becoming more and more present in the workplace, sometimes using online intervention programs, which offer a promising direction in prevention and intervention for health. The objective of this study is to analyze the efficacy of MBIs on psychological variables in the workplace. For this purpose, a search for scientific articles published from 2009 to 2019 was made in the Psicodoc, PsycINFO, and Web of Science databases, where a total of 468 articles were found. After filtering with preestablished inclusion criteria, 24 studies were included in the systematic review and meta-analysis. The results of the meta-analysis suggest that intervention in mindfulness positively influences psychological variables related to employee health and wellbeing. However, it is recommended to continue performing new studies to confirm this finding.
\end{abstract}

Keywords: workplace; meta-analysis; mindfulness; systematic review

\section{Introduction}

Mindfulness is defined as paying full attention to experiences at the present moment, with an open, accepting attitude [1]. In the context of labor, highly stressed employees are exposed to greater health risks, which can increase costs for the organization and even loss of productivity [2]. To counteract these effects, some studies have demonstrated that mindfulness-based interventions (MBIs) can improve mental health [3-5] and employee performance [6].

\subsection{The Potential of Mindfulness}

Mind/body intervention programs are currently enjoying great popularity. Mindfulness-based interventions, such as mindfulness-based cognitive therapy (MBCT) or mindfulness-based stress reduction therapy (MBSRT) are the most commo, and are focused on treatment of mental health problems, such as depression or anxiety [7]. Today, they have strong empirical backing [8]. These programs are conceptually based on traditional mindfulness teaching, that is, they form part of philosophical mindfulness and psychoeducation and act on psychological and neuropsychological mechanisms [9]. In the work environment, development of MBIs is acquiring more presence through online intervention, as it offers a promising new direction for intervention and preventive health $[10,11]$ Such intervention leads to improvement in general subjective wellbeing [12,13], and, therefore, the first 
hypothesis posed for this study was that after mindfulness-based intervention, professionals would have lower levels of stress, anxiety, and depression.

\subsection{Training in Mindfulness in the Workplace}

Organizations are quickly implementing cognitive-behavioral interventions in the workplace to promote employee wellbeing and performance [14]. This may be related to growing violence in the worksite [15]. MBIa can provide employees with competencies and skills for coping with such situations and promote their strengths [16]. Some studies have shown the positive effects of such interventions for promoting health in the workplace [17] and increasing employee engagement [18], enabling them to make a higher-quality effort to achieve results [19]. Along with this evidence, the literature shows the positive repercussions that mindfulness intervention could have on employee psychological health in specific work contexts [20], influencing their ability to cope with adverse situations that may arise [21]. Therefore, keeping these considerations in mind, the second hypothesis was posed, in which we expected employees to show more engagement and resilience after mindfulness intervention.

Job stress is one of the main causes of lowered productivity and absenteeism [22]. It affects psychological health and contributes to burnout $[23,24]$, causing the employee to feel apathetic and lose interest in the job [25]. Emotional intelligence is very important here in coping with such stress and burnout [26]. MBIs also help reduce professionals' stress, which notably and significantly alleviates issues associated with sleep problems [27-29]. Furthermore, many studies have analyzed the relationship of MBIs with other variables, such as psychological distress [30,31], negative and positive affects [32], fatigue [33], and so forth [34,35]. Therefore, organizations are starting up MBIs in the workplace to alleviate employee stress [36,37]. Based on these findings, we posed the third hypothesis, in which we expected employees to have less burnout, emotional exhaustion, fatigue. and negative effects and experience an increase in positive affects and sleep quality, showing greater self-efficacy and better personal wellbeing after participation in mindfulness intervention.

\subsection{This Study}

Mindfulness-based intervention programs in the context of the workplace must be supported by a synthesis of empirical evidence in which the heterogeneity of the different studies shows their efficacy. Meta-analytical studies are intended to overcome the deficiencies and contradictions found in the literature by analyzing the empirical evidence available [38]. This meta-analytical review emphasizes exactly which results the various interventions now show and what influence they exert on psychological variables of employees. Therefore, the main objective of this study was to analyze the efficacy of MBIs on psychological variables of employees.

Its specific objectives were the following: (a) Study the influence of MBIs in reducing stress, anxiety, and depression; (b) analyze engagement, mindfulness, and resilience levels after participation in MBIs, and (c) identify the influence of MBIs on positive and negative affects, burnout, emotional exhaustion, fatigue, sleep quality, self-efficacy, and wellbeing. Based on prior empirical evidence, the following hypotheses were posed:

Hypothesis 1 (H1). Mindfulness intervention reduces stress, anxiety and depression.

Hypothesis 2 (H2). Mindfulness-based intervention programs positively influence engagement, mindfulness, and resilience.

Hypothesis 3 (H3). Mindfulness practice positively influences sleep quality, self-efficacy, wellbeing, positive affects, and reduces burnout, fatigue, emotional exhaustion, and negative affects. 


\section{Materials and Methods}

\subsection{Procedure}

An exhaustive search was made in the Psicodoc, PsycINFO, Web of Science, and other source databases (PsycARTICLES), following the PRISMA recommendations made by Moher et al. [39]. Methodology search filters were applied in the Psicodoc (quasi-experimental, cross-sectional, program evaluation, treatment results, and empirical studies), in the PsycINFO (evaluated by experts and empirical studies) databases and in Web of Science, the filter for document types (articles). This enabled us to make a faster search, discriminating studies that did not meet the preestablished inclusion criteria. The search strategies used the Boolean operator, and. First, a search was made using the following descriptors: "Mindfulness" and "Workplace". After a search in the Psicodoc database yielded no results, a second search was made in the databases selected (Psicodoc, PsycINFO, Web of Science, and PsycARTICLES), using the following descriptors: "Mindfulness") AND "Workplace". A total of 495 articles were found for screening and review. The search period included studies published from 2009 to October of 2019. Articles were reviewed during the month of November 2019, when the texts dealing with the relationship between mindfulness and intervention carried out in the workplace were analyzed.

\subsection{Inclusion and Exclusion Criteria}

The inclusion criteria were: (1) Studies published from January 2009 to October 2019, (2) in English or Spanish, (3) evaluated the relationship between mindfulness and the workplace, (4) were on intervention and provided the numerical data necessary for a meta-analysis, (5) complete text available, and (6) evaluated by experts.

The exclusion criteria set were: (1) Duplicate studies, (2) only qualitative data, (3) published in a language other than English or Spanish, (4) on other matters related to mindfulness or the workplace, (5) not on intervention, (6) theses, chapters in books, books, or reviews, and (7) did not present the quantitative results necessary for the meta-analysis.

\subsection{Data Extraction and Synthesis}

For article selection, first, the title and the abstract were reviewed to apply the first exclusion criterion. Then, the complete text was thoroughly read by three members of the team to be able to apply the rest of the conceptual and methodological criteria set.

The characteristics of the workplace, participants, and interventions were coded by two reviewers (M.M.M. and J.G.S.). In those cases, where there were discrepancies, they were resolved in meetings with the senior researcher (M.C.P.-F.) to reach a consensus.

\subsection{Data Analysis: Meta-Analysis}

The Cochrane Review Manager (RevMan) version 5.3 was used to test the heterogeneity of the studies included, effect size, data quality, etc. [40]. For data analysis, the Intervention Review option (inverse variance) with random-effects standardized means was used to test intervention effectiveness, since the results of the interventions differed from each other. Interpretation of the effect-size estimates was in line with Cohen's [41] guidelines, where 0.2 was a small effect, 0.5 medium, and 0.8 large. The direction of the effect sizes was considered favorable if the result showed improvement during the intervention. Heterogeneity was considered substantial if $I^{2} \geq 75 \%$, moderate from $50 \%$ to $75 \%$, and low when $I^{2} \leq 25 \%$ [42].

\subsection{Qualification of Risk of Bias}

The Cochrane Collaborations risk-of-bias tool was used [43]. Individual studies were scored for risk (1: low risk, 2: high risk, and 3: unclear risk). The potential bias of the studies included was 
assessed by inspection of distribution of points on the meta-analysis plots. Two researchers evaluated the risk of bias independently, and disagreements were resolved by consensus in a meeting with the senior researcher.

\section{Results}

\subsection{Study Selection}

Figure 1 shows the study selection process (Flowchart). Of 468 studies identified in the Psicodoc, PsycINFO, and Web of Science databases and 27 additional records identified through other sources (PsycARTICLES), 65 duplicates were eliminated. A total of 430 studies were screened, leaving 426 for review. Then, 393 more were eliminated for various reasons. The PRISMA diagram in Figure 1 shows the flow of articles from the original search to the final inclusion. In the end, 24 studies were included in the systematic review and meta-analysis.

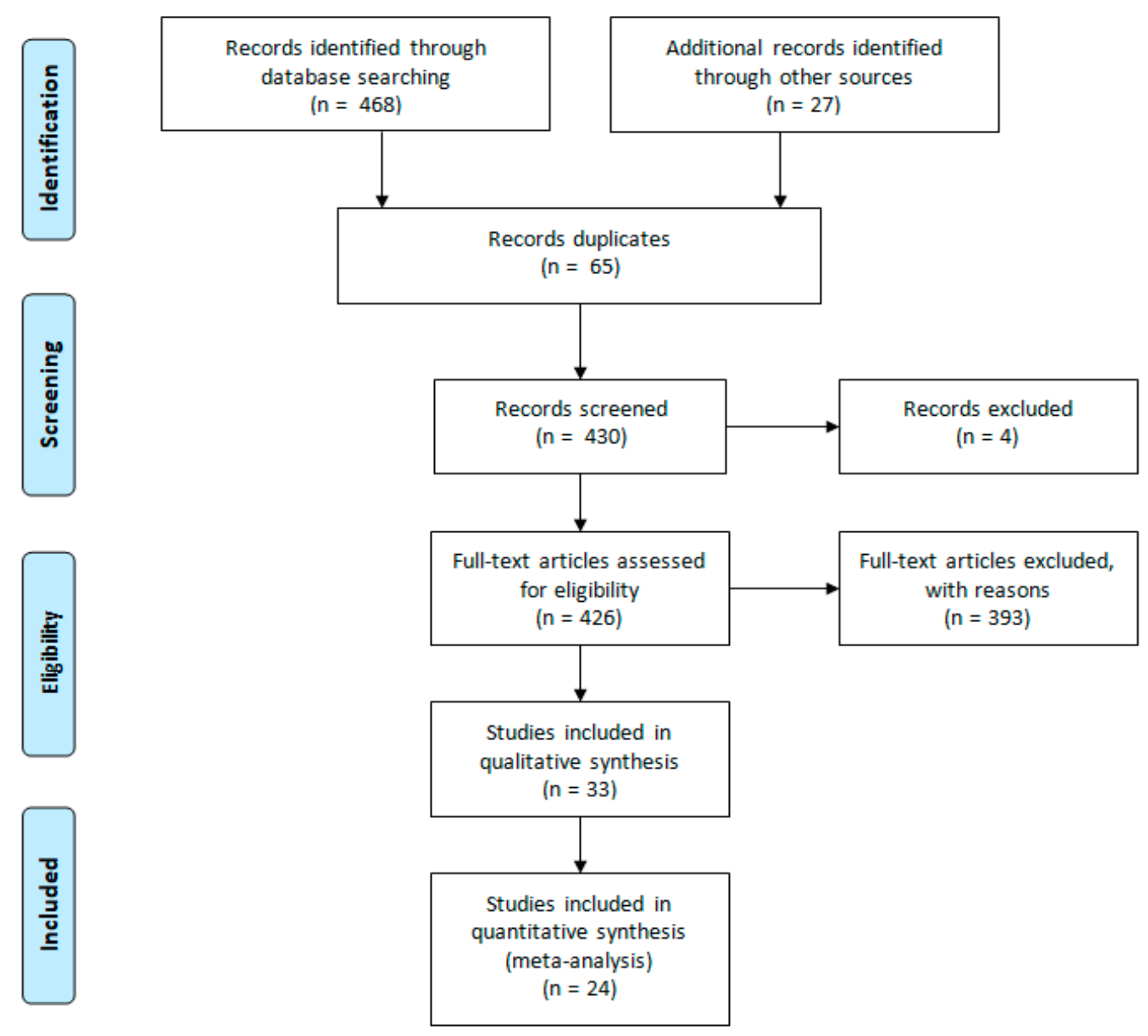

Figure 1. Mindfulness in the workplace: PRISMA flowchart with steps in article selection [39].

Table 1 shows the characteristics of the 24 articles included. The various studies carried out mindfulness-based intervention, evaluating the efficacy of the interventions in comparisons extracted in the pretest-post-test results. 
Table 1. Studies dealing with the relationship between mindfulness and thworkplace.

\begin{tabular}{|c|c|c|c|c|}
\hline Authors & Study Design & Place & $\begin{array}{c}\text { Total } \\
\text { Intervention } \\
\text { Time } \\
\end{array}$ & Intervention Sessions \\
\hline Mäkiniemi and Heikkilä-Tammi [32] & 2-group controlled trial & Finland & 10 months & $10 \times 2.5 \mathrm{~h}$ sessions \\
\hline Bonilla and Padilla [7] & Single-group uncontrolled trial & Puerto Rico & 8 weeks & $8 \times 90$ min sessions + daily practice at home \\
\hline Dobie, Tucker, Ferrari, and Rogers [12] & Single-group uncontrolled trial & Australia & 8 weeks & $3 \times 30 \mathrm{~min}$ sessions/week \\
\hline Kersemaekers et al. [9] & Single-group uncontrolled trial & Germany & 10 weeks & 2 full days $+82.5 \mathrm{~h}$ sessions + daily practice at home with $10 \mathrm{~min}$ audio recording \\
\hline Gallego, Aguilar-Parra, Cangas, Rosado, and Langer [8] & Controlled trial, 4 studies & Spain & 8 weeks & $2 \times 30 \mathrm{~min} /$ week + daily practice at home with audio recording \\
\hline Klatt, Norre, Reader, Yodice, and White [17] & 2-group controlled trial & Denmark & 8 weeks & First intervention personal attendance $(1 \mathrm{~h})+$ daily practice at home with audio recording \\
\hline van Berkel, Boot, Proper, Bongers, and van der Beek [18] & 2-group controlled trial & Netherlands & 6 months & $90 \mathrm{~min} / \mathrm{week}$ \\
\hline García-Rubio, Luna, Castillo, and Rodríguez-Carvajal [5] & 2-group controlled trial & Spain & 6 weeks & 2 sessions/week $+10 \mathrm{~min}$ audio \\
\hline Brito [3] & Single-group controlled trial & Chile & 8 weeks & $8 \times 2-1 / 2 \mathrm{~h}$ sessions \\
\hline Slatyer, Craigie, Heritage, Davis, and Rees [6] & 3-group controlled trial & Australia & 6 months & One attended session + daily practice at home with 25 min audio recording \\
\hline Huang, Li, Huang, and Tang [1] & 2-group controlled trial & China & 8 weeks & $2 \times 1 \mathrm{~h}$ sessions/week $+45 \mathrm{~min}$ daily practice at home \\
\hline Blanco et al. [16] & 2-group controlled trial & Spain & 3 months & $2 \times 3 \mathrm{~h}$ sessions at work + daily practice at home with audio recording \\
\hline Trowbridge, Lawson, Andrews, and Pecora [37] & Single-group uncontrolled trial & Kansas & 6 weeks & 2 sessions/week + daily 20 min practice at home with audio recording \\
\hline Crain, Schonert-Reich, and Roeser [28] & 2-group controlled trial & Canada & 8 weeks & Total 11 sessions $(36 \mathrm{~h})$ \\
\hline Duchemin, Steinberg, Marks, Vanover, and Klatt [34] & 2-group controlled trial & Ohio & 8 weeks & Weekly $1 \mathrm{~h}$ sessions + daily practice at home with 80 -min audio recording \\
\hline Horan and Taylor [35] & Single-group uncontrolled trial & Kentucky & 10 weeks & Weekly $1 \mathrm{~h}$ meetings \\
\hline Lilly et al. [11] & 2-group controlled trial & Washington & 7 weeks & Online (daily $20-45$ min audio) \\
\hline Grégoire and Lachance [33] & 2-group controlled trial & New York & 5 weeks & 15 min daily audio sessions \\
\hline Pang and Ruch [36] & 3-group controlled trial & Switzerland & 8 weeks & Weekly $1 \mathrm{~h}$ sessions + daily practice at home with audio recording $(20-40 \mathrm{~min})$ \\
\hline Bartlett, Lovell, Otahal, and Sanderson [30] & 2-group controlled trial & New York & 5 weeks & Weekly 20 min meditations. Total intervention time $7.5 \mathrm{~h}$ \\
\hline Wolever et al. [2] & 3-group controlled trial & North Carolina & 12 weeks & $1.15 \mathrm{~h}$ intervention/week. Total intervention $14 \mathrm{~h}$ \\
\hline Aikens et al. [10] & 2-group controlled trial & Michigan & 7 weeks & Online. Total 8 classes $30-45 \mathrm{~min}$ \\
\hline Craigie et al. [21] & Single-group uncontrolled trial & New York & 4 weeks & Weekly $1.30 \mathrm{~h}$ Session +30 min daily practice at home \\
\hline Chin, Slutsky, Raye, and Creswell [14] & 2-group uncontrolled trial & Florida & 6 weeks & First day attended workshop $+25 \mathrm{~min}$ guided practice ( 5 days/week) \\
\hline
\end{tabular}


The sample size varied from nine participants in the study by Dobie et al. [12] to 279 in the study by Kersemaekers et al. [9].

The time that the interventions took differed in the various studies. The study by Craigie et al. [21] lasted 4 weeks, while the study by Mäkiniemi and Meikkila-Tammi [31] lasted 10 months. However, in most of the studies, for example, those by Gallego et al. [8] and Huang et al. [1], the duration was 8 weeks. The program methodology in most of them was intervention with personal attendance, with mindfulness practice at home, while listening to audio recordings. However, some studies used online intervention $[10,11]$.

Table 1 shows the results of the studies selected for systematic review and meta-analysis. To extract the information in this study, they were coded in the following process: (1) authors and year of publication, (2) study design, (3) place, (4) total intervention time, and (5) intervention sessions.

\subsection{Results of Meta-Analysis}

The findings of the meta-analysis of mindfulness in the workplace and its variables are presented in Table 2. A consistently positive effect of mindfulness was found to be related to the different variables.

Table 2. Mindfulness in the workplace and influence with different variables (meta-analytical estimates of effect).

\begin{tabular}{|c|c|c|c|c|c|c|c|}
\hline \multirow{2}{*}{ Results } & \multirow{2}{*}{$\mathbf{k}$} & \multirow{2}{*}{ SMD } & \multicolumn{2}{|c|}{ 95\% Confidence Interval } & \multirow{2}{*}{$\begin{array}{c}\text { Significance } \\
p\end{array}$} & \multicolumn{2}{|c|}{ Heterogeneity } \\
\hline & & & Lower Limit & Upper Limit & & $\mathbf{Z}$ & $I^{2}(\%)$ \\
\hline \multicolumn{8}{|l|}{ Mindfulness } \\
\hline MAAS & 7 & -1.28 & -2.95 & 0.39 & 0.13 & 1.50 & $99 \%$ \\
\hline FFMQ (Multifaceted measurements) & 2 & -0.89 & -1.05 & -0.72 & $<0.0001$ & 10.56 & $0 \%$ \\
\hline FFMQ Observing & 2 & -1.04 & -1.41 & -0.67 & $<0.0001$ & 5.46 & $0 \%$ \\
\hline FFMQ Non-reactivity & 2 & -1.10 & -1.48 & -0.72 & $<0.0001$ & 5.72 & $0 \%$ \\
\hline FFMQ Non-judging & 2 & -0.66 & -1.06 & -0.26 & 0.001 & 3.24 & $14 \%$ \\
\hline Other measurement instruments & 5 & -1.73 & -4.04 & 0.57 & 0.14 & 1.47 & $98 \%$ \\
\hline \multicolumn{8}{|l|}{ Depression, anxiety, and stress } \\
\hline Depression & 7 & 1.43 & -0.05 & 2.92 & 0.06 & 1.90 & $98 \%$ \\
\hline Negative affect & 4 & 0.42 & 0.09 & 0.75 & 0.01 & 2.53 & $0 \%$ \\
\hline Fatigue & 2 & 0.84 & 0.54 & 1.13 & $<0.0001$ & 5.57 & $0 \%$ \\
\hline Burnout & 4 & 2.02 & -0.84 & 4.87 & 0.17 & 1.38 & $99 \%$ \\
\hline Emotional Exhaustion & 2 & 0.01 & -0.46 & 0.48 & 0.97 & 0.04 & $0 \%$ \\
\hline Engagement & 2 & 0.08 & -0.32 & 0.49 & 0.68 & 0.41 & $52 \%$ \\
\hline Resilience & 3 & -0.35 & -0.74 & 0.04 & 0.07 & 1.78 & $51 \%$ \\
\hline Wellbeing & 3 & -2.68 & -6.64 & 1.29 & 0.19 & 1.32 & $99 \%$ \\
\hline Sleep quality & 4 & 2.05 & -0.79 & 4.89 & 0.16 & 1.42 & $99 \%$ \\
\hline
\end{tabular}

Note. $\mathrm{SMD}=$ standardized mean difference. Instruments used: Mindfulness (CAMM, CAMS-R, FFMQ, FFM, Five-Facet Mindfulness Questionnaire, Freiburg Mindfulness Scale, KIMS, and MAAS); depression (BDI-II, CCAPS-34, CES-D, DASS, DASS21, and STAI); anxiety (CCAPS-34, DASS, DASS21, SAS and STAI); stress (C-SOSI, DASS, DASS21, EEP-14, PSM-9, PSS, PSS-10, PSS-14, PSM-9, and PSQ); positive and negative affect (PANAS); fatigue (CIS, Fatigue Scale and the Checklist Individual Strength Questionnaire); burnout (BM, BO, MBI, and ProQOL); emotional exhaustion (CDPE and MBI); engagement (UWES); resilience (CD-RISC and CD-RISC10); engagement (UWES); wellbeing (WHO-Five); job satisfaction (JSQ); and, sleep quality (JSS and PSQI).

\subsection{Risk of Bias in Studies Included}

The publication bias in the majority of cases was low. In general, no high risk of bias was observed. The funnel plots are presented below with the results found for risk of bias with the different variables (Figure 2). As may be observed in the figure, one study by van Berkel et al. [18], which analyzed the mindfulness, depression, anxiety and stress variables, was the one at most risk of bias. 


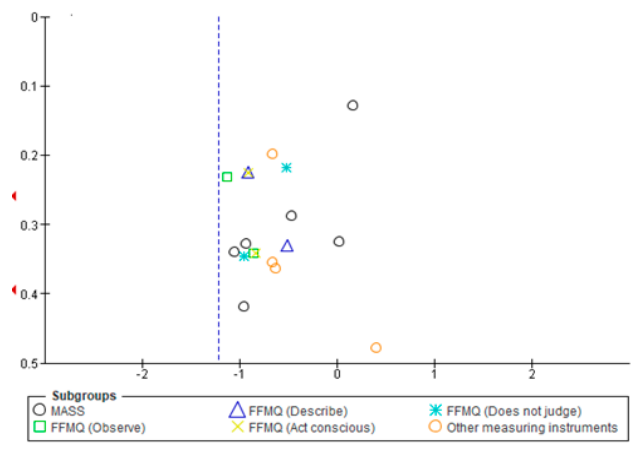

(a)

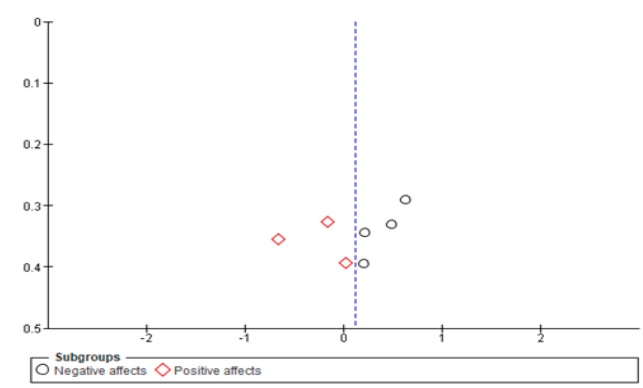

(c)

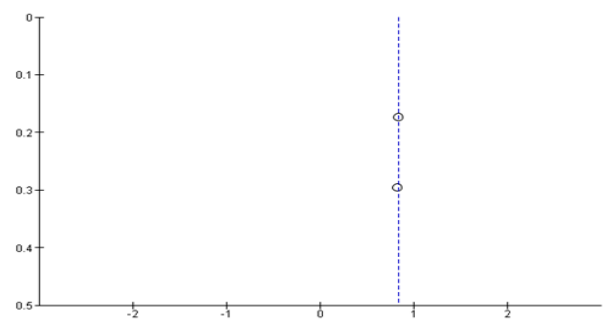

(e)

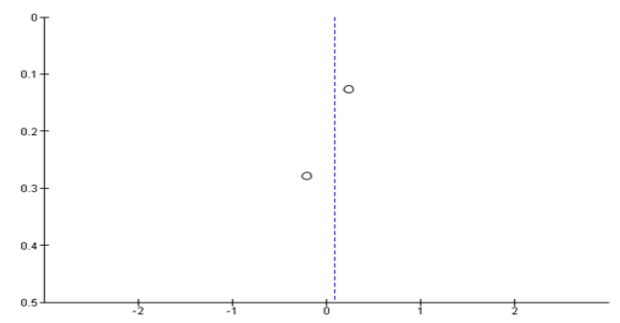

(g)

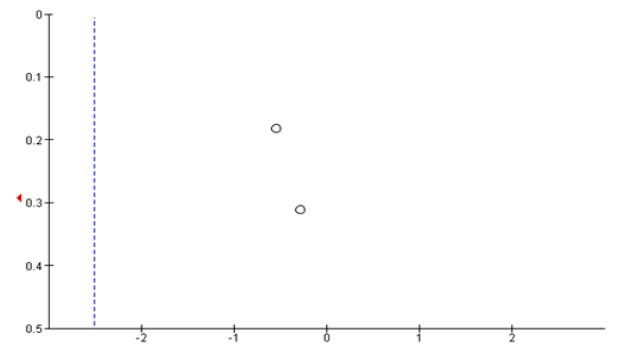

(i)

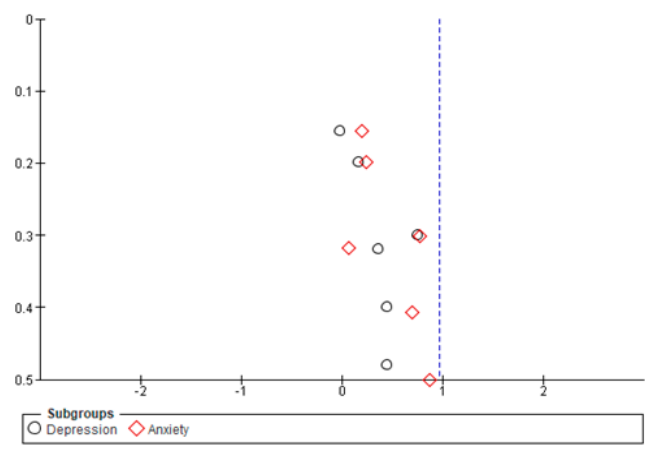

(b)

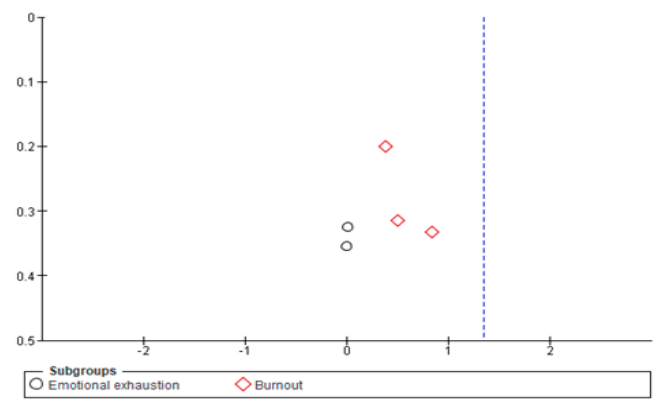

(d)

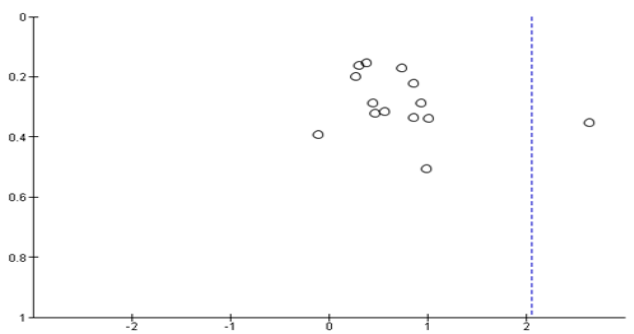

(f)

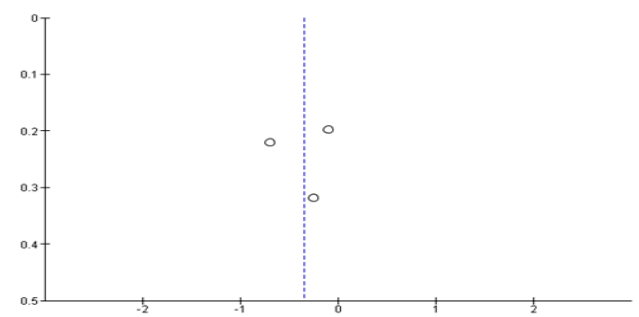

(h)

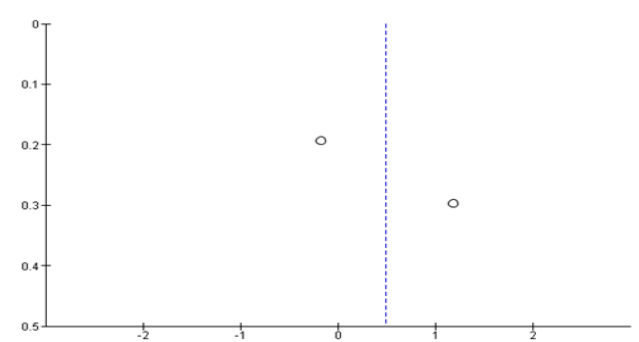

(j)

Figure 2. Risk of bias for all variables. (a) Mindfulness. (b) Depression and anxiety. (c) Negative and positive affects. (d) Emotional exhaustion and burnout. (e) Fatigue. (f) Stress. (g) Engagement. (h) Resilience. (i) Wellbeing. (j) Quality of sleep. 


\subsection{Meta-Analytical Differences between Attended and Online Intervention}

To check the efficacy of attended (Figure 3) and online (Figures 4 and 5) interventions, the meta-analysis was performed for each of them, as shown in Figures 3-5.

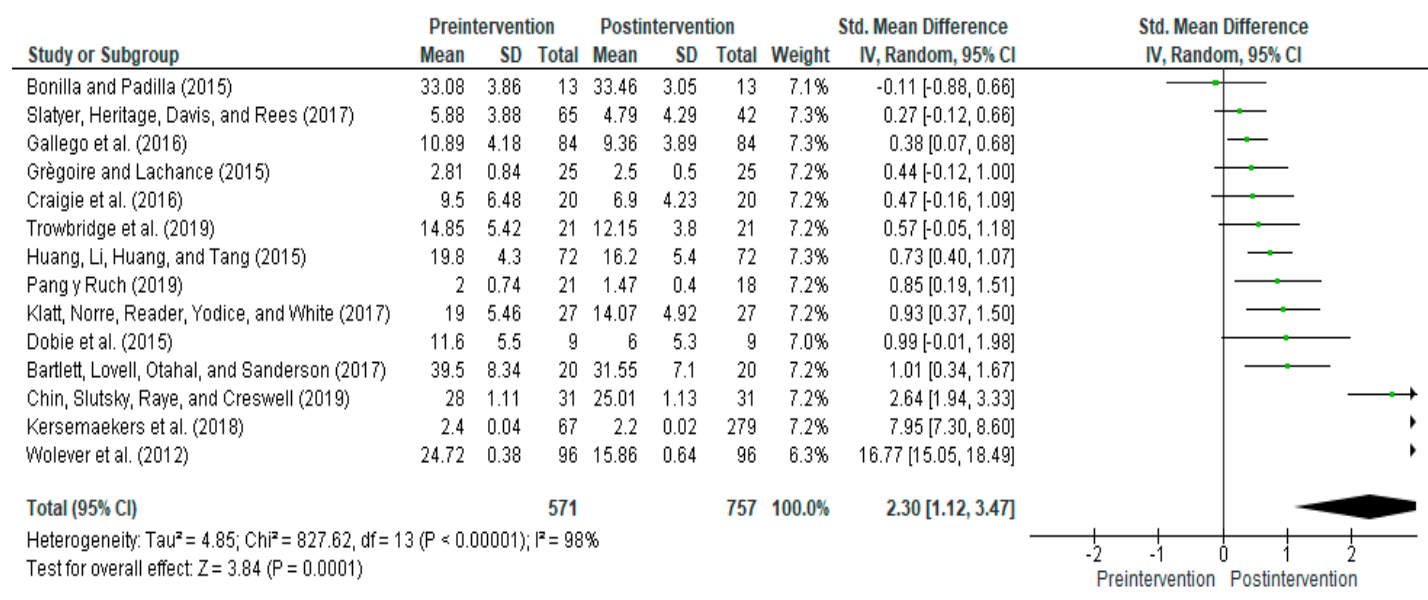

Figure 3. Meta-analysis of mindfulness in the workplace and influence on stress (attended intervention).

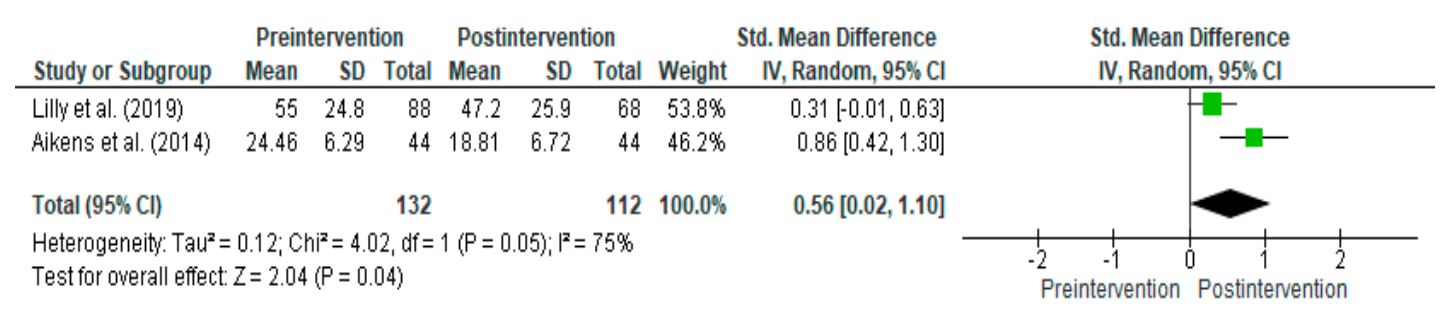

Figure 4. Meta-analysis of mindfulness in the workplace and influence on stress (online intervention).
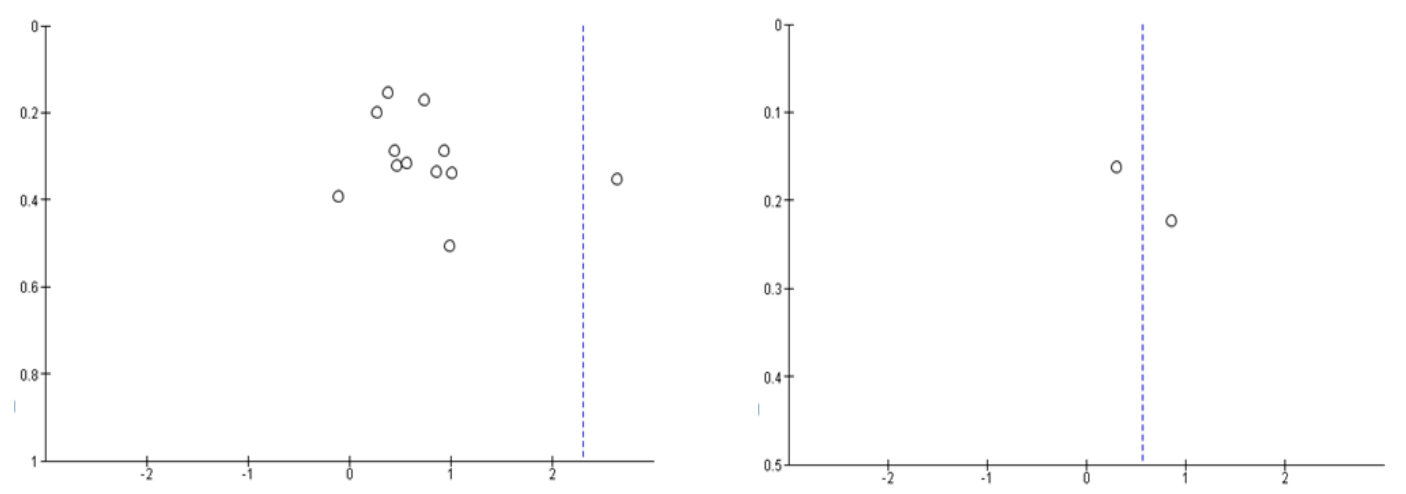

Figure 5. Risk of bias stress (attended intervention-online intervention).

\section{Discussion}

\subsection{Summary of Evidence}

The objective of this study was to analyze the efficacy of MBIs for psychological variables in the workplace. The studies concentrated on different psychological aspects and, therefore, different instruments. In view of the findings of those studies, the first hypothesis referring to reduction in stress, anxiety, and depression after mindfulness-based intervention programs were applied was confirmed. Thus, in the study by Klatt et al. [17], after mindfulness intervention, health, and wellbeing of employees improved, depression, anxiety, and stress levels were lower. Results in most of the other studies, among which was the study by Dobie et al. [12], were similar. Furthermore, practicing 
mindfulness in the work context was an effective strategy, not only for reducing exhaustion and perceived stress, but also for increasing employee satisfaction [1].

The second hypothesis, in which it was expected that employees would show more engagement, mindfulness, and increased resilience, was supported by several studies. The study by Grégoire and Lachance [33] found increased levels of mindfulness and engagement [17] after intervention in mindfulness. After intervention, resilience also increased in participants, enabling them to cope with more adverse everyday situations at work [6,21].

The mindfulness programs carried out in the workplace motivated employees, reinforcing job performance and intensifying their wellbeing [36]. Thus, such programs reduce negative [32] and increase positive emotions [7]. They also improved sleep quality [28], generating conditions that reduced emotional exhaustion and burnout [16]. These findings confirmed the third hypothesis, in which it was expected that after MBI, employees would have lower levels of burnout, emotional exhaustion, fatigue, and negative affect, and would experience an increase in positive affects and sleep quality, showing better self-efficacy, and personal wellbeing. Other data indicate that after intervention, turnover also diminishes [35].

Therefore, when mindfulness-based intervention was carried out in the work-place to reduce stress and depression or to improve sleep quality, a favorable effect was observed after its completion [2]. Nevertheless, with online intervention, such as the intervention carried out by Aikens et al. [10] and Lilly et al. [11], heterogeneity was found to be lower. In spite of this, according to Sard-Pecka et al. [31], both types of interventions (attended and online) reduce stress levels. In favor of online interventions, it could be said that they are usually more economical, since there is no instructor present, scheduling is more flexible, and they can be done from home [4].

After the meta-analysis, the efficacy of intervention could be confirmed, since most of the studies had favorable results after mindfulness practice. However, some studies included were highly heterogenous, possibly because of the variety of measurement instruments used, which limits the scope of the results [38]. Bias was somewhat uncertain in some domains. However, we believe that this may have been influenced by unsuitability of the Cochrane Collaborations risk assessment tool for this type of study.

Nonetheless, among the main objectives of mindfulness are improvement in performance [5] and wellbeing [14]. Therefore, the mindfulness-based intervention programs favor improved health and, thereby, quality of life [9].

\subsection{Study Limitations}

One of the main limitations of this study was the sample sizes, which did not vary much from one to another. Another of the limitations was related to the search strategy, as it concentrated on the Psicodoc, PsycINFO, and Web of Science databases, and, therefore, some studies published in other resources may have been involuntarily omitted. Quantitative data were lacking in the results section of some of the studies reviewed and so could not be included in the meta-analysis. Another of the limitations was the variety of instruments used to measure the variables studied. Finally, there were very few studies on online interventions.

\subsection{Future Lines of Research}

A future line of research recommended is widening knowledge on this subject with new studies, including other variables, such as emotional intelligence, which would enable new evidence to be found. In general, we suggest that new studies include quantitative results on variables in the pretest and post-test so that they can be used in meta-analytical studies, which would help advance research in this field. 


\subsection{Practical Applications of the Results}

The implications of this study are relevant, insofar as they emphasize the benefits of mindfulness-based intervention for employee quality of life. Therefore, given the proximity and availability of such intervention, it should be put into practice in business to improve employee health, wellbeing, and quality of life.

\section{Conclusions}

This review of studies on mindfulness-based intervention confirmed its positive influence on several psychological aspects. The results analyzed suggest that this type of intervention is effective in the organizational context and is an effective solution for job performance, leading to the improved wellbeing of employees.

Therefore, training in mindfulness in the workplace can be an effective focus for employees, since the results show a favorable effect on employee health after application of mindfulness intervention, improving quality of life and physical and psychological wellbeing.

Author Contributions: M.d.C.P.-F., M.d.M.M.J., and J.G.S.S. contributed to the conception and design of the review. J.J.G.L. and I.M.R. applied the search strategy. All authors applied the selection criteria. All authors completed the assessment of risk of bias. All authors analyzed the data and interpreted data. M.d.M.M.J., M.d.C.P.-F., I.M.R., and J.G.S.S. wrote this manuscript. M.d.C.P.-F. and J.J.G.L. edited this manuscript. M.d.C.P.-F. was responsible for the overall project. All authors have read and agreed to the published version of the manuscript.

Funding: This research received no external funding.

Acknowledgments: This study was performed with the collaboration of the Almeria Provincial Government. Part of it was done with Predoctoral Contract Aid for Ph.D. Training (PRE2018-085434), who granted José Gabriel Soriano Sánchez under Project Ref.: EDU2017-88139-R, funded by the State Program for Research, Development and Innovation Oriented toward Challenges to Society, in the framework of the State Plan for Science and Technology Research and Innovation, and cofounding from the European Union Structural Funds.

Conflicts of Interest: The authors declare no conflict of interest.

\section{References}

1. Huang, S.L.; Li, R.H.; Huang, F.Y.; Tang, F.C. The potential for mindfulness-based intervention in workplace mental health promotion: Results of a randomized controlled trial. PLoS ONE 2015, 10, e0138089. [CrossRef] [PubMed]

2. Wolever, R.; Bobinet, K.; McCabe, K.; Mackenzie, E.; Fekete, E.; Kusnic, C.; Baime, M. Effective and Viable Mind-Body Stress Reduction in the Workplace: A Randomized Controlled Trial. J. Occup. Health Psychol. 2012, 17, 246-258. [CrossRef] [PubMed]

3. Brito, G. Programa de reducción del estrés basado en la atención plena (mindfulness): Sistematización de una experiencia de su aplicación en un hospital público semi-rural del sur de Chile. Psicoperspectivas 2011, 10, 221-242. [CrossRef]

4. Fish, J.; Brimson, J.; Lynch, S. Mindfulness interventions delivered by technology without facilitator involvement: What research exists and what are the clinical outcomes? Mindfulness 2016, 7, 1011-1023. [CrossRef] [PubMed]

5. García-Rubio, C.; Luna, T.; Castillo, R.; Rodríguez-Carvajal, R. Impacto de una intervención breve basada en mindfulness en niños: Un estudio piloto. Rev. Interuniv. Form. Prof. 2016, 87, 61-74.

6. Slatyer, S.; Craige, M.; Heritage, B.; Davis, S.; Rees, C. Evaluating the effectiveness of a brief Mindful Self-Care and Resiliency (MSCR) intervention for nurses: A wait-list controlled trial. Mindfulness 2017, 9, 534-546. [CrossRef]

7. Bonilla, K.; Padilla, Y. Estudio piloto de un modelo grupal de meditación de atención plena (mindfulness) de manejo de la ansiedad para estudiantes universitarios en Puerto Rico. Rev. Puertorriquena Psicol. 2015, 26, 72-87.

8. Gallego, J.; Aguilar-Parra, J.M.; Cangas, A.J.; Rosado, A.; Langer, A.I. Efecto de intervenciones mente/cuerpo sobre los niveles de ansiedad, estrés y depresión en futuros docentes de educación primaria: Un estudio controlado. Rev. Psicodidáctica 2016, 21, 87-101. [CrossRef] 
9. Kersemaekers, W.; Rupprecht, S.; Wittmann, M.; Tamdjidi, C.; Falke, P.; Donders, R.; Speckens, A.; Rohls, N. A workplace mindfulness intervention may be associated with improved psychological well-being and productivity. A preliminary field study in a company setting. Front. Physiol. 2018, 9, 1-11. [CrossRef]

10. Aikens, K.A.; Astin, J.; Pelletier, K.R.; Levanovich, K.; Baase, C.M.; Park, Y.Y.; Bodnar, C.M. Mindfulness Goes to Work: Impact of an Online Workplace Intervention. J. Occup. Med. 2014, 56, 721-731. [CrossRef]

11. Lilly, M.; Calhoun, R.; Painter, I.; Beaton, R.; Stangenes, S.; Revere, D.; Baseman, J.; Meischke, H. Destress 9-1-1-an online mindfulness-based intervention in reducing stress among emergency medical dispatchers: A randomised controlled trial. Occup. Environ. Med. 2019, 76, 705-711. [CrossRef] [PubMed]

12. Dobie, A.; Tucker, A.; Ferrari, M.; Rogers, J.M. Preliminary evaluation of a brief mindfulness-based stress reduction intervention for mental health professionals. Australas. Psychiatry 2016, 24, 42-45. [CrossRef] [PubMed]

13. Wersebe, H.; Lieb, R.; Meyer, A.H.; Miche, M.; Mikoteit, T.; Imboden, C.; Hoyer, J.; Badere, K.; Hatzinger, M.; Gloster, A.T. Well-being in major depression and social phobia with and whitout comorbidity. Int. J. Clin. Health Psychol. 2018, 18, 201-208. [CrossRef] [PubMed]

14. Chin, B.; Slutsky, J.; Raye, J.; Creswell, J.D. Mindfulness Training Reduces Stress at Work: A Randomized Controlled Trial. Mindfulness 2019, 10, 627-638. [CrossRef] [PubMed]

15. López-García, C.; Ruiz-Hernández, J.A.; Llor-Zaragoza, L.; Llor-Zaragoza, P.; Jiménez-Barbero, J.A. User Violence and Psychological Well-being in Primary Health-Care Professionals. Eur. J. Psychol. Appl. Legal. Context 2018, 10, 57-63. [CrossRef]

16. Blanco, L.M.; García, C.; Moreno-Jiménez, M.L.; Rodríguez de la Pinta, S.; Moraleda, S.; Garrosa, E. Intervención breve basada en ACT y mindfulness: Estudio piloto con profesionales de Enfermería en UCI y Urgencias. AL PRACTICE. Int. J. Psychiat Clin. 2017, 17, 57-73.

17. Klatt, M.; Norre, C.; Reader, B.; Yodice, L.; White, S. Mindfulness in motion: A mindfulness-based intervention to reduce stress and enhance quality of sleep in scandinavian employees. Mindfulness 2017, 8, 481-488. [CrossRef]

18. van Berkel, J.; Boot, C.R.L.; Proper, K.I.; Bongers, P.M.; van der Beek, A.J. Effectiveness of a Worksite Mindfulness-Related Multi- Component Health Promotion Intervention on Work Engagement and Mental Health: Results of a Randomized Controlled Trial. PLoS ONE 2014, 9, e84118. [CrossRef]

19. Martos, A.; Pérez-Fuentes, M.C.; Molero, M.M.; Gázquez, J.J.; Simón, M.M.; Barragán, A.B. Burnout y engagement en estudiantes de Ciencias de la Salud. Eur. J. Investig. Health Psychol. Educ. 2018, 8, 23-36. [CrossRef]

20. Williams, V.; Ciarrochi, J.; Deane, F.P. On being mindful, emotionally aware, and more resilient: Longitudinal pilot study of police recruits. Aust. Psychol. Soc. 2010, 45, 274-282. [CrossRef]

21. Craigie, M.; Slatyer, S.; Hegney, D.; Osseiran-Moisson, R.; Gentry, E.; Davis, S.; Dolan, T.; Rees, C. A pilot Evaluation of a Mindful Self-care and Resiliency (MSCR) Intervention for Nurses. Mindfulness 2016, 7 , 764-774. [CrossRef]

22. Arredondo, M.; Sabaté, M.; Valveny, N.; Langa, M.; Dosantos, R.; Moreno, J.; Botella, L. A mindfulness training program based on brief practices $(\mathrm{M}-\mathrm{PBI})$ to reduce stress in the workplace: A randomised controlled pilot study. J. Occup. Med. 2017, 23, 40-51. [CrossRef] [PubMed]

23. Pérez-Fuentes, M.C.; Molero, M.M.; Gázquez, J.J.; Simón, M.M. Analysis of Burnout Predictors in Nursing: Risk and Protective Psychological Factors. Eur. J. Psychol. Appl. Legal. Context 2019, 11, 33-40. [CrossRef]

24. Vizoso-Gómez, C.; Arias-Gundín, O. Resiliencia, optimismo y burnout académico en estudiantes universitarios. Eur. J. Educ. Psychol. 2018, 11, 47-59. [CrossRef]

25. Pérez-Fuentes, M.C.; Gázquez, J.J.; Ruiz, M.D.; Molero, M.M. Inventory of Overburden in Alzheimer's Patient Family Caregivers with no Specialized Training. Int. J. Clin. Health Psychol. 2017, 17, 56-64. [CrossRef]

26. Pérez-Fuentes, M.C.; Gázquez, J.J.; Mercader, I.; Molero, M.M. Brief Emotional Intelligence Inventory for Senior Citizens (EQ-i-M20). Psicothema 2014, 26, 524-530. [CrossRef]

27. Amutio, A.; Franco, C.; Sánchez, L.C.; Pérez-Fuentes, M.C.; Gázquez, J.J.; Van Gordon, W.; Molero, M.M. Effects of Mindfulness Training on Sleep Problems in Patients with Fibromyalgia. Front. Physiol. 2018, 9, 1-8. [CrossRef]

28. Crain, T.L.; Schonert-Reichl, K.A.; Roser, R.W. Cultivating teacher mindfulness: Effects of a randomized controlled trial on work, home, and sleep outcomes. J. Occup. Health Psychol. 2017, 22, 138-152. [CrossRef] 
29. Gázquez, J.J.; Pérez-Fuentes, M.C.; Molero, M.M.; Oropesa, N.F.; Simón, M.M.; Saracostti, M. Sleep Quality and the Mediating Role of Stress Management on Eating by Nursing Personnel. Nutrients 2019, 11, 1731. [CrossRef]

30. Bartlett, L.; Lovell, P.; Otahal, P.; Sanderson, K. Acceptability, Feasibility, and Efficacy of a Workplace Mindfulness Program for Public Sector Employees: A Pilot Randomized Controlled Trial with Informant Reports. Mindfulness 2016, 8, 639-654. [CrossRef]

31. Sard-Pecka, T.E.; Martín-Asuero, A.; Oller, M.T.; Calvoa, A.; Santesteban-Echarri, O. Estudio comparativo entre un programa de reducción del estrés basado en mindfulness presencial y online en población general española. Psiquiatr. Biológica 2019, 26, 73-79. [CrossRef]

32. Mäkiniemi, J.P.; Heikkilä-Tammi, K. Promoting Sustainability: The Effects of Workplace Mindfulness Training. Electron. J. Bus. Ethics Organ. Stud. 2018, 23, 20-28.

33. Grégoire, S.; Lachance, L. Evaluation of a Brief Mindfulness-Based Intervention to Reduce Psychological Distress in the Workplace. Mindfulness 2015, 6, 836-847. [CrossRef]

34. Duchemin, A.M.; Steinberg, B.A.; Marks, D.R.; Vanover, K.; Klatt, M. A Small Randomized Pilot Study of a Workplace Mindfulness-Based Intervention for Surgical Intensive Care Unit Personnel: Effects on Salivary $\alpha$-Amylase Levels. J. Occup. Med. 2015, 57, 393-409. [CrossRef] [PubMed]

35. Horan, K.A.; Taylor, M.B. Mindfulness and self-compassion as tools nt health behavior change: An evaluation of a workplace intervention pilot study. J. Contextual Behav. Sci. 2018, 8, 8-16. [CrossRef]

36. Pang, D.; Ruch, W. Fusing Character Strengths and Mindfulness Interventions: Benefits for Job Satisfaction and Performance. J. Occup. Health Psychol. 2019, 24, 150-162. [CrossRef]

37. Trowbridge, K.; Lawson, L.M.; Andrews, A.; Pecora, J. Preliminary Investigation of Workplace-Provided Compressed Mindfulness-Based Stress Reduction with Pediatric Medical Social Employees. Health Soc. Work 2017, 42, 1-8. [CrossRef]

38. García, A.M.; Sánchez-Meca, J.; Álvarez, F.J.; Rubio-Paricio, M.; Navarro-Mateu, F. Neuroticismo e ideas suicidas: Un estudio meta-analítico. Rev. Esp. Salud. Pública. 2018, 92, 1-18.

39. Moher, D.; Liberati, A.; Tetzlaff, J.; Altman, D.G.; Altman, D.; Antes, G.; Tugwell, P. Preferred reporting items for systematic reviews and meta-analyses: The PRISMA statement (Chinese edition). J. Chin. Integr. Med. 2009, 7, 889-896. [CrossRef]

40. Sánchez-Meca, J.; Ato, M. Meta-análisis: Una alternativa metodológica a las revisiones tradicionales de la investigación. In Tratado de Psicología General I: Historia, Teoría y Método; Arnau, J., Carpintero, H., Eds.; Alhambra: Madrid, Spain, 1989; pp. 617-669.

41. Cohen, J. A power primer. Psychol. Bull. 1992, 112, 155-159. [CrossRef]

42. Higgins, J.P.T.; Thompson, S.G.; Deeks, J.J.; Altman, D.G. Measuring inconsistency in meta-analyses. Br. Med. J. 2003, 327, 557-560. [CrossRef] [PubMed]

43. Higgins, J.P.T.; Altman, D.G.; Gotzsche, P.C.; Juni, P.; Moher, D.; Oxman, A.D.; Savovic, J.; Schulz, K.F.; Weeks, L.; Sterne, J.A.C. The Cochrane Collaboration's tool for assessing risk of bias in randomised trials. $\mathrm{Br}$. Med. J. 2011, 343, d5928. [CrossRef] [PubMed]

(C) 2020 by the authors. Licensee MDPI, Basel, Switzerland. This article is an open access article distributed under the terms and conditions of the Creative Commons Attribution (CC BY) license (http://creativecommons.org/licenses/by/4.0/). 